\title{
US doctors call for tracking of suicides among medical trainees
}

- Cite as: CMAJ 2019 January 7;191:E26. doi: 10.1503/cmaj.109-5694

Posted on cmajnews.com on Dec. 6, 2018.

$\mathrm{T}$ he American Medical Association (AMA) is seeking better data on suicides among medical students, residents and fellows. The association's house of delegates recently called on the Liaison Committee on Medical Education and the Accreditation Council for Graduate Medical Education to collect data on trainee suicides to "identify patterns that could predict such events."

"We believe that collecting data on the incidence of suicide among physicians in training will help us identify the systemic factors that contribute to this problem, and ultimately save lives," said AMA board member Dr. Ryan Ribeira. The association will also report on the "most efficient and accurate mechanism" to study these deaths and make recommendations for action at its next annual meeting.

Medicine has the highest suicide rate of any profession. It's estimated that about 400 doctors die by suicide in the United States each year, but it's hard to say for sure because many deaths may be mislabelled as accidents.

A recent Canadian survey found that nearly one in five physicians have thoughts of suicide at some point in their lives; $8 \%$ had thought about suicide in the past 12 months. Medical residents, female physicians and doctors in the first five years of practice are particularly vulnerable.

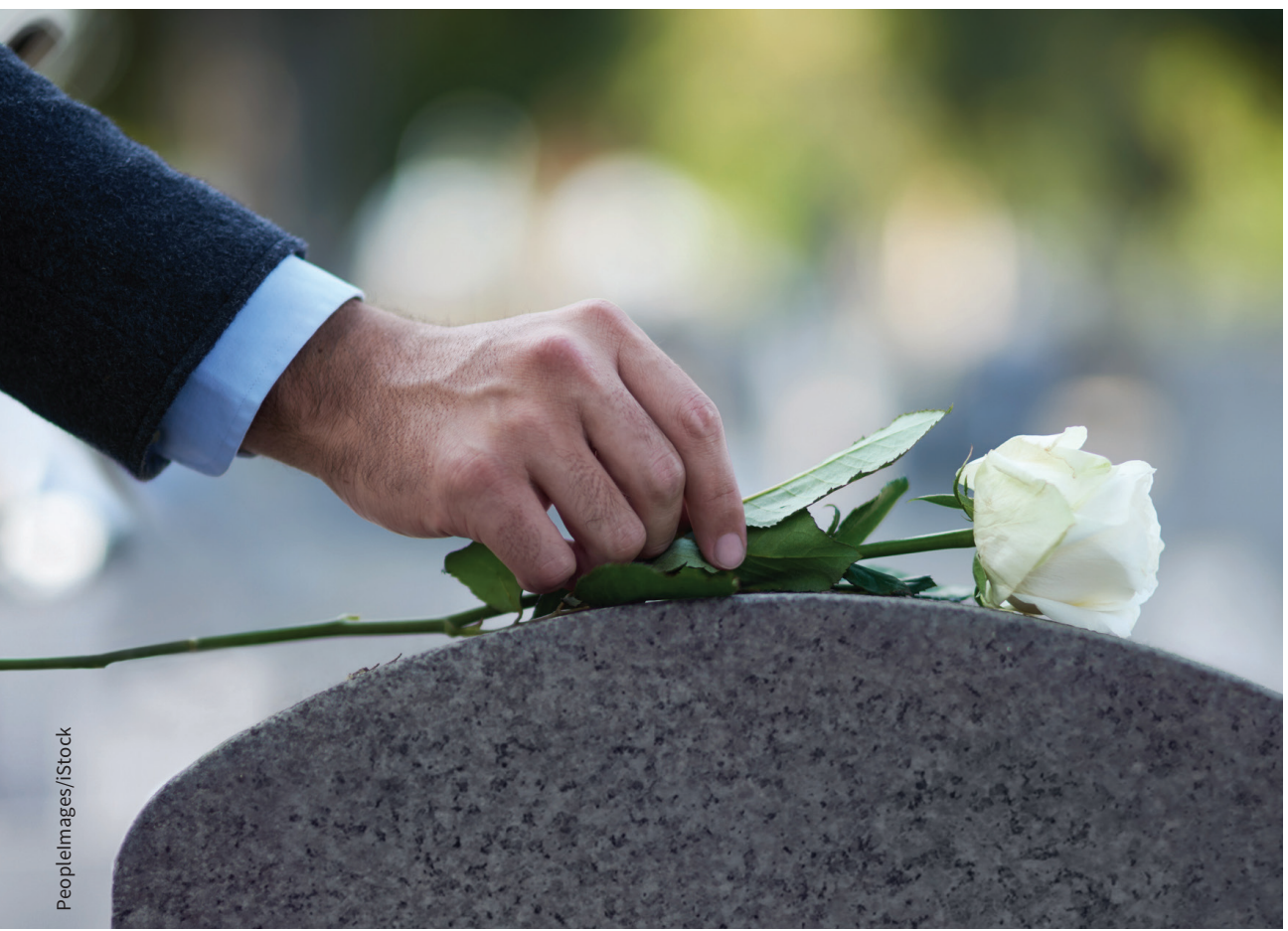

Medical trainees are particularly vulnerable to suicide, but their deaths are seldom counted or investigated.
But shame and silence around physician and trainee suicides persist. Dr. Pamela Wible, an Oregon-based family physician, has counted more than 700 suicides in the past five years among physicians in her extended network. Medical schools and hospitals don't track or investigate these deaths, she told CMAJ. "They erase them off the schedule, move their patients to someone else, and it's like they never lived."

There's no formal tracking of physician suicides in Canada, but physician health experts say the rate is probably the same or higher than in the United States, based on anecdote. The Canadian Medical Association (CMA) has no plans to track suicides among trainees or practising physicians, "the latter of which would prove more complicated," according to a statement provided to CMAJ. But like the AMA, the association is seeking to better understand factors that could predict these deaths.

CMA is putting together a follow-up report to its national physician health survey that "explores the relationship between personal, behavioural, and occupational factors on suicidal ideation, among other outcomes." The report will inform the work of the association's new vice-president of physician health and wellness, Dr. Caroline Gérin-Lajoie. In a recent statement, she attributed high rates of burnout in medicine to "budget cuts and higher volumes of patients and higher complexity of care."

According to Gérin-Lajoie, "physicians have always experienced stress, but these changes have brought us to a point where we need to address wellness and burnout much more directly."

Lauren Vogel, CMAJ 